\title{
Upper Extremity Impairments and Activities in Children with Bilateral Cerebral Palsy
}

\author{
Bulent Elbasan, ${ }^{1,}{ }^{*}$ Elmas Bozkurt, ${ }^{2}$ Deran Oskay, ${ }^{1}$ and Cigdem Oksuz ${ }^{3}$ \\ ${ }^{1}$ Gazi University, Faculty of Health Sciences, Department of Physiotherapy and Rehabilitation, Ankara \\ ${ }^{2}$ Gazi University, Institute of Health Sciences, Ankara \\ ${ }^{3}$ Hacettepe University, Faculty of Health Sciences, Department of Occupational Therapy, Ankara
}

"Corresponding author: Bulent Elbasan, Gazi University, Faculty of Health Sciences, Department of Physiotherapy and Rehabilitation, Emniyet Mh, Muammer Yasar Bostanci Cd. No: 14, Besevler, Ankara, Turkey. Tel: +90-3122162630, Fax: +90-5324672923, E-mail: bulentelbasan@gmail.com

Received 2017 June 29; Revised 2017 August 02; Accepted 2017 September 24.

\begin{abstract}
Background: There is a lack of evidence about the upper extremity impairments and function in children with diparetic cerebral palsy.

Objectives: This study was planned to investigate the upper extremity impairments, dexterity, grip strength and function in the daily living activities in children with diparetic cerebral palsy (CP).

Methods: Eighteen children with diparetic CP and 15 typical peers between the ages 5 - 12 years were included in the study. Manual Ability Classification System (MACS) was used for the classification of upper extremity fine motor skills; WeeFIM for activities of daily living; Abilhand-Kids for the manual abilities; and Pediatric Evaluation of Disability Inventory (PEDI) for the disability in the daily living activities respectively. Grip strength was evaluated with Jamar Hand Dynamometer, hand functions were assessed with Nine-hole Peg Test and Jebsen-Taylor test.

Results: Children with diparetic CP were affected in manual abilities and functions, grip strength, activities of daily living, and levels of disability and the results were statistically significant $(\mathrm{P}<0.05)$.

Conclusions: As a conclusion, upper extremity impairments, dexterity, grip strength, and functions in the activities of daily living are affected in children with diparetic CP. Physiotherapy interventions for upper extremities and hand should be included as well as the lower extremities in the treatment of the spastic diparetic children.
\end{abstract}

Keywords: Cerebral Palsy, Upper Extremity, Rehabilitation

\section{Background}

Cerebral Palsy (CP) is a developmental disorder, characterized by a group of movements and postural impairments due to a lesion occurring in the motor cortex of the brain for any reason in prenatal, natal, or postnatal period and is non-progressive (1). Diplegia is a spastic type of CP in which lower extremities are affected more than the upper extremities. Muscle weakness is significant in trunk, postural and antigravity muscles. In addition, proprioception and tactile sense insufficiencies are also observed (2-4).

In children with diplegia, although lower extremity involvement is observed in varying degrees, datas showing how upper extremity and hand functions are affected are insufficient. However, whatever the diagnosis is, upper extremity functions are on top of the factors providing the participation in daily living for these children. In addition to being predominantly among the most significant components affecting the functionality of upper extremity, hands play a key role in carrying out the activities of daily living activities. Disorders of hands and arms may be affected in children with CP (5-7). While numerous studies focus on lower extremity disorders, walking abnormalities and postural control disorders of the children with $\mathrm{CP}$, when considered from a viewpoint of upper extremity functions, hand dexterity, and according to international classification of function (ICF); it is observed that studies on upper extremity impairments and activities are insufficient. In addition, existing studies showing a correlation between the self-care and manual skills were carried out focusing more on children with unilateral CP (8). On the other hand, since the target group of this study is composed of children with diplegia, it is important to include their typical peers as a control group.

\section{Objectives}

This study was planned to investigate the impairments, skills and strength of the upper extremity and their effect on the activity level in children with bilateral CP. The results will help to figure out the needs for the rehabilitation of the upper extremity in this population. 


\section{Methods}

A power analysis using the Gpower computer program indicated that a total sample of 11 subjects for study group and 11 subjects for control group would be needed to detect large effects with $94 \%$ power using a t test between means with alpha at 0.05 . So the study included 18 voluntary children with spastic diplegia, aged between 5 and 12 years with no mental problem according to their health report, and able to cooperate in terms of communication, and 15 typically developing peers with normal development characteristics as the control group with a total of 33 children.

Families included in the study were informed about the method and purpose of the study. The families who accepted to participate in the study were evaluated and signed an informed consent form. Following the evaluation by non-interventional clinical research ethics board of Hacetepe University, our study was approved as confirming to medical ethics (project Ref No. GO15/516, date of evaluation 29.07.2015, decision No. GO 15/516 - 13).

Inclusion criteria for children with $\mathrm{CP}$ between the ages 5 - 12 years; classified in levels I, II, III of the Gross Motor Function Classification System (GMFCS); having no visual perceptional problems; able to follow verbal instructions; having noninvasive intervention on hand and upper extremity in the last 6 months. The typical developed group was composed of the children referred from our university school offering mainstream education. Children who had an upper extremity problem that might affect upper extremity functions were excluded.

The demographic information of the children as age, gender, gestational age, type of birth, body mass index (BMI), dominant hand, surgical and Botox A injection history were recorded. The children were asked about the hand they prefer to use for writing and in the activities requiring strength in the daily living activities, and their dominant hands were thus recorded.

Gross motor function was classified using the GMFCS (9), self-initiated hand function was classified with MACS (10), WeeFIM (11) was used to assess the activities of daily living, Turkish version of Abilhand-Kids (12) was used to evaluate manual abilities, and Pediatric Evaluation of Disability Inventory (PEDI) (13) was used to assess the activities of daily living. The grip strength was evaluated with Jamar Hand Dynamometer (Lafayette Instrument, USA) (14) hand functions were assessed by Nine-hole Peg Test (15) and Jebsen-Taylor Test (16).

1. Gross Motor Function Classification System (GMFCS): Children with CP below the age of 12 years were divided into five levels, based on self-initiated movements, sitting and walking (9).
2. Manual Abilities Classification System (MACS): Manual ability classification system was developed in order to classify the abilities to grip objects by hand, during the activities of daily living in children with CP aged $4-18$ years. MACS classifies in 5 levels. While Level I defines the child with CP having minor limitations when compared with normally developing child, Level $V$ includes the children that are unable to grip objects and children having limited abilities at the highest degree to carry out even simple activities (10).

3. Functional Independence Measure for children (WeeFIM): Activities of daily living were evaluated with WeeFIM. It includes a total of 18 items in 6 domains as selfcare, sphincter control, transfers, locomotion, and communication, social and cognitive dimensions.18 points represents to fully dependent where as 126 points represents to fully independent (11).

4. Abilhand-Kids: Abilities of the hand of $\mathrm{CP}$ was evaluated by using Abilhand-Kids questionnaire. It consists of 21 daily living activities asked reported by parents. Scores are ' $0=$ Impossible', ' $1=$ Difficult,' and ' $2=$ Easy'. At most a total of 42 points can be obtained. The Turkish version of this system was already carried out (12).

5. Pediatric Evaluation of Disability Inventory (PEDI): Turkish version of Functional Skills dimension of PEDI was used to manifest motor development levels reflecting themselves on functions of children with $\mathrm{CP}$. The child is assigned scores as " $0=$ Unable" and " $1=$ Capable". At the end of each dimension, scores of the said section are summed up and functional skills (FS) total score is obtained by adding the scores of all subcategories (13).

6. Nine-Hole Peg Test: Hand function of the children was assessed by Nine-Hole Peg test. Children were asked to take the pegs from a container, one by one, and place them into the holes on the board as quickly as possible. Scores are based on the time taken to complete the test activity, recorded in seconds. This procedure was applied on dominant and non-dominant hand (14).

7. Jebsen-Taylor Hand Function Test: Jebsen-Taylor Hand Function Test consists of a series of sub-tests representing hand functions in daily life and evaluates hand skills. Scores are based on the time taken to complete the test activity (15).

8. Jamar Hand Dynamometer: Jamar Hand Dynamometer was used to evaluate hand strength. All the measurements were done according to American Society of Hand Therapists (ASHT) recommended position. For the test procedure, 3 measurements were taken with oneminute breaks given inbetween each hand grip test, and averages were recorded in kilograms (16).

Outcome measures were evaluated by a 15 year experienced physiotherapist in pediatrics. All the assessment 
was done in a clinical setting appropriate for the age of the target population. The assessment procedure was started after a 15 minutes rest of the children.

\subsection{Statistical Analysis}

Statistical analyses of the study were carried out with "statistical package for social sciences" (SPSS) version 18.0 (SPSS INC., Chicago, IL, USA) software. Age, gestational age, and body mass index were provided by using crosstabs. Categorical variables were noted in frequency and percentage. Conformity of the data to normal distribution was analyzed with visual (histogram and probability graphs) and analytical(Kolmogorov-Smirnov/Shapiro-Wilk tests) methods. Descriptive analyses were presented by using mean and standard deviations for normally distributed variables. WeeFIM, ABILHAND-Kids and PEDI parameters were compared by using student-T test between the groups. Descriptive analyses were presented using means and intervals between quadrants for the non-normally distributed and ordinal variables. Jebsen-Taylor Test, 9-hole PEG Test, dominant and non-dominant side strength results parameters were presented by using Mann-Whitney U Test, since they are non-normally distributed variables. The level of significance was set at $\mathrm{P}<0.05$ (17).

\section{Results}

There was no difference between the general characteristics of the groups. The demographic characteristics of the cases are given in Table 1 . The five of the children with $\mathrm{CP}$ were Level I according to gross motor function system, 8 were at Level II, and 5 were at level III. According to MACS, 5 of the children with CP were at Level I, while 13 of them were at Level II.

Average scores of WeeFIM, Abilhand Kids, and PEDI of children with CP were as 104.61, 32.83 and 163.72 respectively; and the average scores of healthy children comprising the control group were 123.53, 41.13 and 193.13 respectively. The control group had statistically significant scores in WeeFIM, Abilhand Kids score, and PEDI score $(\mathrm{P}<0.05)$ between the groups.

Based on the grip strength assessment carried out by the hand dynamometer, a statistically significant difference was observed between both dominant and nondominant upper extremities $(\mathrm{P}<0.05)$ (Table 3$)$. The control group had greater scores in all JTHFT dimensions, which were statistically significant and the result is presented in Table 4.

\section{Discussion}

This is the first study on evaluating the hand and upper extremity function, dexterity, strength and activity in spastic diplegia. Our primary results indicate that manual skills, functions, and grip strength, along with the activities of daily living and functional skills are affected in children with diplegia compared to their healthy peers. It was concluded that, while implementing a physiotherapy rehabilitation program, it should be emphasized that upper extremity function should be taken into account as well as the lower extremities in children with spastic diplegia.

Although the disorders that develop in CP, occurs depending on the size and region of the insult in the brain, the effect definitely appears on a certain region in the body, and the rest of the body is also believed to be affected as well. But there is less clear data about the non-involved side and/or the part of the body, which was the main objective of this study.

According to the demographic characteristics, the only difference was the gestational age between the groups, which was an expected result. One of the most common reasons of $\mathrm{CP}$ is the natal factors. Although there are some studies showing no association between the gestational age and CP, the number of children under the term age is higher than the term age in this population.

In children with $\mathrm{CP}$, certain restrictions are observed in upper extremity functions and the skills in the activities of daily living depending on motor activation $(18,19)$. In a study by Law et al., it was suggested that manual functions were affected more in especially tetraparetic and diparetic $\mathrm{CP}$ cases compared to triparetic cases. Also, in the same study, the recorded WeeFIM scores of triparetic children with single upper extremity involvement were observed as higher compared to hemiparetic and diparetic children, and when compared with their peers, they showed similar performance (18). However, this result that manifests contradiction with the current study also puts forth that manual dexterity and functions may be affected from other variables such as trunk control and spasticity which were not considered in this study (20). Other than this, the reason for insufficiency in the skills in daily living compared to their peers might be linked to the use of their hands more to compensate lower extremities. In addition, it was believed that, the use of assisting devices for mobilization purposes would limit the use of their hands in such skills as feeding, dressing and eating. Similarly, when checked the functional skills section of PEDI, the fact that children with CP have insufficiencies compared to their peers put forth that, they were dependent in their daily living activities. Although children included in the study were independent on GMFCS levels of I, II, and III, limitations were 
Table 1. The Demographic Characteristics of the Children with Diparetic Cerebral Palsy and the Control Group

\begin{tabular}{|c|c|c|c|}
\hline & $\mathrm{CP}(\mathrm{n}=18)$ & $\operatorname{Control}(\mathbf{n}=15)$ & $\mathbf{P}$ \\
\hline Age (years) & $8(6.75 / 9.25)$ & $9(7 / 10)$ & 0.464 \\
\hline Gender (female/male) & $9 / 9$ & $6 / 9$ & 0.729 \\
\hline Delivery (normal/caesarian section) & $6 / 12$ & $7 / 8$ & 0.493 \\
\hline Dominant hand (right/left) & $12 / 6$ & $12 / 3$ & 0.458 \\
\hline Gestational age (weeks) & $30(27.75 / 38)$ & $40(40 / 40)$ & $<0.001$ \\
\hline Body mass index & $14.87(13.64 / 17.20)$ & $16.06(14.63 / 18.35)$ & 0.219 \\
\hline
\end{tabular}

Table 2. The Functional Test Results of the Children with Diparetic Cerebral Palsy and the Control Group

\begin{tabular}{|c|c|c|c|c|}
\hline & CP, Mean $\pm S D(n=18)$ & Control, Mean $\pm S D(n=15)$ & $\mathbf{t}$ & $\mathbf{P}$ \\
\hline WeeFIM (total) & $104.61 \pm 19.99$ & $123.53 \pm 5.79$ & -3.828 & $<0.001$ \\
\hline ABILHAND-Kids & $32.83 \pm 7.61$ & $41.13 \pm 1.73$ & -4.491 & $<0.001$ \\
\hline PEDI & $163.72 \pm 26.0$ & $193.13 \pm 4.69$ & -4.708 & $<0.001$ \\
\hline
\end{tabular}

Abbreviations: SD, Standard Deviation; CP, Cerebral Palsy; PEDI, Pediatric Evaluation of Disability Inventory; ABILHAND- Kids, Manual Ability for Children with Upper Limb Impairments; WeeFIM, Functional Independence Measure for Children

Table 3. The Comparison of the Dominant and Non-Dominant Grip Strength of the Groups

\begin{tabular}{|c|c|c|c|c|}
\hline & CP Median (IQR) (Score) & Control Median (IQR) (Score) & $\mathbf{Z}$ & $\mathbf{P}$ \\
\hline Dominant side (kg) & $3.75(1.88 / 5.25)$ & 8. $00(4 / 12)$ & -2.374 & 0.018 \\
\hline Non-Dominant side (kg) & $3.00(1.75 / 5.38)$ & 7. $00(4 / 14)$ & -2.233 & 0.026 \\
\hline
\end{tabular}

Abbreviation: IQR, Interquartile Range

observed in their independency in goal-oriented skills in their daily living activities.

According to manual skills and grip strength of children, there was difference between the groups, and dominant and non-dominant hands. As also shown in other studies, activities of daily living needs the coordination of both hands (21). For instance, if we want to pour water into a glass, one hand holds the glass (stabilization) while the other pours the water (movement). Therefore, manual skills as grip strength of both hands should not be expected to be the same. While such a difference can be linked to neuromusculoskeletal problems, it may also develop depending on the attitudes within the family. Overprotective attitudes of families towards their children with $\mathrm{CP}$ and environmental conditions may also be noted among the problems affecting the level of independence of these children $(22,23)$. Thus, when rehabilitation programs are prepared, it would especially become important to modify the environmental conditions according to their needs (24). In addition, in a study showing that hand grip strength and manual abilities are indirectly related with manual skills, it was concluded that activities requiring skills are not quite related with abilities used in the daily life (3). Therefore, literature showed that, it would be important to have such functional therapies as constraintinduced movement therapy and bimanual therapy for increasing the skills rather than increasing the manual abilities and strength in children with CP(25). While, in a study by Sakzewski et al, it was reported that non-dominant grip strength, more than $1 \mathrm{~kg}$, would be sufficient in bimanual activities (26), Arnould et al. in their study conducted on 136 children with CP found that grip strength in $13 \%$ of non-dominant hand was below $1 \mathrm{~kg}$. While the children included in both studies had different types of CP, grip strength of both hands was found to be similar since children included in this study had spastic diplegia. Although in a study done by Arnould et al. more than half of the children with diplegia showed bilateral impairment in gross manual dexterity and grip strength (27).

There are lack of skills and functions of the hand in different types of $\mathrm{CP}$ (7). It is also known that upper extremities and hand functions are affected in different types 
Table 4. Comparison of the Results of Jebson Taylor Test in Children with Diparetic Cerebral Palsy and the Control Group

\begin{tabular}{|c|c|c|c|c|}
\hline & CP Median (IQR) (Score) & Control Median (IQR) (Score) & $\mathbf{Z}$ & $\mathbf{P}$ \\
\hline \multicolumn{5}{|l|}{ Turning over cards (sn) } \\
\hline Dominant & $8.60(5.25 / 10.57)$ & $5.25(3.39 / 8.16)$ & -2.314 & 0.021 \\
\hline Non-dominant & $7.41(5.29 / 10.49)$ & $5.30(3.93 / 6.20)$ & -2.802 & 0.005 \\
\hline \multicolumn{5}{|c|}{ Picking up empty and large canes } \\
\hline Dominant & $4.32(3.38 / 7.79)$ & $2.81(2.18 / 3.17)$ & -4.032 & $<0.001$ \\
\hline Non-dominant & $5.48(3.91 / 8.07)$ & $2.77(2.12 / 3.74)$ & -3.688 & $<0.001$ \\
\hline \multicolumn{5}{|c|}{ Picking up small objects (sn) } \\
\hline Dominant & $8.64(7.63 / 13.11)$ & $5.73(5.16 / 6.34)$ & -4.158 & $<0.001$ \\
\hline Non-dominant & $10.97(7.49 / 18.56)$ & $5.68(5.09 / 6.70)$ & -4.122 & $<0.001$ \\
\hline \multicolumn{5}{|l|}{ Simulated feeding (sn) } \\
\hline Dominant & $19.78(13.30 / 36.94)$ & $10.26(9.56 / 11.97)$ & -3.724 & $<0.001$ \\
\hline Non-dominant & $19.15(22.40 / 50.66)$ & $15.64(10.92 / 19.43)$ & -4.014 & $<0.001$ \\
\hline Total score & $106.04(70.18 / 146.15)$ & $55.69(46.22 / 60.78)$ & -4.230 & $<0.001$ \\
\hline
\end{tabular}

Table 5. Comparison of the Results of the 9 Hole Peg Test in Children with Diparetic Cerebral Palsy and the Control Group

\begin{tabular}{|c|c|c|c|c|}
\hline & CP Median (IQR) (Score) & Control Median (IQR) (Score) & $\mathbf{z}$ & $\mathbf{P}$ \\
\hline \multicolumn{5}{|l|}{ Placing (sn) } \\
\hline Dominant & $21.99(16.17 / 41.28)$ & $13.17(10.78 / 14.90)$ & -3.977 & $<0.001$ \\
\hline Non-dominant & $26.42(21.52 / 47.86)$ & $14.58(12.02 / 15.90)$ & -4.519 & $<0.001$ \\
\hline \multicolumn{5}{|l|}{ Pick up (sn) } \\
\hline Dominant & $11.70(9.51 / 19.11)$ & $6.54(4.95 / 8.02)$ & -4.122 & $<0.001$ \\
\hline Non-dominant & $15.26(9.72 / 21.18)$ & $6.97(4.78 / 8.30)$ & -4.483 & $<0.001$ \\
\hline Total Score & $84.48(59.15 / 135.72)$ & $40.99(32.83 / 46.20)$ & -4.483 & $<0.001$ \\
\hline
\end{tabular}

Abbreviation: IQR, Interquartile Range

of CP (3). The four extremities are affected in diparetic $\mathrm{CP}$, in which the lower extremities are more involved (28). In another study, fine motor skills of cases with diparetic $\mathrm{CP}$ were shown as not different from those of their peers (29). However, in this study, it was observed that children with diparetic $\mathrm{CP}$ were inadequate in their fine motor skills compared to the healthy peers. When checked the definition of $\mathrm{CP}$, it is known that corticospinal pathways are affected at the early stages depending on the insult in the brain (3). Therefore both, susceptibility of these pathways and the over protective attitudes of the family members on these children for meeting their needs, restricts the use of the hand in children with CP. In addition, it is common that individuals with CP use upper extremities and hands more intensively in balance, righthining, and protective reactions. So this may be the reason for not using their hands in the daily activities. Insufficiencies, especially in the fine motor skills, negatively affect the level of independence in daily life. It should be also considered that, if a child has some limitation in the daily living activities, there will also be some constraints at their social integration and participation.

Evaluation of hand functions in cases with different types of CP and comparison with each other would allow a more clear understanding of this issue. In addition, increasing the number of cases in the study and the presence of a control group with an intervention program would put forth the benefits of physiotherapy program.

Consequently, it is concluded that, the hand function, dexterity and skills of children with $\mathrm{CP}$ are affected, and correspondingly certain constraints are observed in their daily life. Beginning from the early years of life, it is necessary to focus on functional approaches oriented towards activities of daily living to improve upper extremity and 
manual skills, in addition to the interventions oriented towards the disorder within the scope of ICF; such as muscle strength, spasticity, and range of motion, in physiotherapy and rehabilitation programs for such children. In addition to the physiotherapy rehabilitation programs, it would be also quite important to benefit from occupational therapy programs helping to overcome their limitations for participation in daily life and decreasing their level of disability.

\section{References}

1. Barry MJ, Butler C, Gardner JM. Early diagnosis and interventional therapy in cerebral palsy. 3rd ed. New York: Marcel Dekker Inc; 2001.

2. Almeida KM, Fonseca ST, Figueiredo PRP, Aquino AA, Mancini MC. Effects of interventions with therapeutic suits (clothing) on impairments and functional limitations of children with cerebral palsy: a systematic review. Braz J Phys Ther. 2017;21(5):307-20. doi: 10.1016/j.bjpt.2017.06.009. [PubMed: 28712784].

3. Arnould C, Bleyenheuft Y, Thonnard JL. Hand functioning in children with cerebral palsy. Front Neurol. 2014;5:48. doi: 10.3389/fneur.2014.00048. [PubMed: 24782821].

4. Shumway C, Woollacott MH. Motor control: Translating research into clinical practice. Pennsylvania: Lippincott Williams and Wilkins; 2007.

5. Klingels K, Demeyere I, Jaspers E, De Cock P, Molenaers G, Boyd $\mathrm{R}$, et al. Upper limb impairments and their impact on activity measures in children with unilateral cerebral palsy. Eur J Paediatr Neurol. 2012;16(5):475-84. doi: 10.1016/j.ejpn.2011.12.008. [PubMed: 22244966].

6. Klingels K, Feys H, De Wit L, Jaspers E, Van de Winckel A, Verbeke G, et al. Arm and hand function in children with unilateral cerebral palsy: a one-year follow-up study. Eur J Paediatr Neurol. 2012;16(3):257-65. doi: 10.1016/j.ejpn.2011.08.001. [PubMed: 21940183].

7. Fedrizzi E, Pagliano E, Andreucci E, Oleari G. Hand function in children with hemiplegic cerebral palsy: prospective follow-up and functional outcome in adolescence. Dev Med Child Neurol. 2003;45(2):8591. [PubMed: 12578233].

8. Ostensjo S, Carlberg EB, Vollestad NK. Everyday functioning in young children with cerebral palsy: functional skills, caregiver assistance, and modifications of the environment. Dev Med Child Neurol. 2003;45(9):603-12. [PubMed: 12948327]

9. Palisano RJ, Hanna SE, Rosenbaum PL, Russell DJ, Walter SD, Wood EP, et al. Validation of a model of gross motor function for children with cerebral palsy. Phys Ther. 2000;80(10):974-85. [PubMed: 11002433].

10. Akpinar P, Tezel CG, Eliasson AC, Icagasioglu A. Reliability and crosscultural validation of the Turkish version of Manual Ability Classification System (MACS) for children with cerebral palsy. Disabil Rehabil. 2010;32(23):1910-6. doi: 10.3109/09638281003763796. [PubMed: 20373857].

11. Erkin G, Aybay C, Kurt M, Keles I, Cakci A, Ozel S. The assessment of functional status in Turkish children with cerebral palsy (a preliminary study). Child Care Health Dev. 2005;31(6):719-25. doi:10.1111/j.13652214.2005.00565.x. [PubMed: 16207230].
12. Oksuz C, Alemdaroglu I, Kilinc M. Reliability and validity of the Turkish version of ABILHAND-Kids' questionnaire in a group of patients with neuromuscular disorders. Physiother Theory Pract. 2017;17:1-8.

13. Erkin G, Elhan AH, Aybay C, Sirzai H, Ozel S. Validity and reliability of the Turkish translation of the Pediatric Evaluation of Disability Inventory (PEDI). Disabil Rehabil. 2007;29(16):1271-9. doi 10.1080/09638280600964307. [PubMed: 17654002].

14. Mathiowetz V, Weber K, Kashman N, Volland G. Adult norms for the nine hole peg test of finger dexterity. Occup Ther J Res. 1985;5:24-38.

15. Jebsen RH, Taylor N, Trieschmann RB, Trotter MJ, Howard LA. An objective and standardized test of hand function. Arch Phys Med Rehabil. 1969;50(6):311-9. [PubMed: 5788487].

16. Mathiowetz V, Weber K, Volland G, Kashman N. Reliability and validity of grip and pinch strength evaluations. J Hand Surg Am. 1984;9(2):2226. [PubMed: 6715829].

17. SPSS Inc. . Statistical package for social sciences, Version 18.0. Chicago, Ill, USA: SPSS Inc; 2008.

18. Law K, Lee EY, Fung BK, Yan LS, Gudushauri P, Wang KW, et al. Evaluation of deformity and hand function in cerebral palsy patients. J Orthop Surg Res. 2008;3:52. doi: 10.1186/1749-799X-3-52. [PubMed: 19105802].

19. Park ES, Sim EG, Rha DW. Effect of upper limb deformities on gross motor and upper limb functions in children with spastic cerebral palsy. Res Dev Disabil. 2011;32(6):2389-97. doi: 10.1016/j.ridd.2011.07.021. [PubMed: 21821392].

20. Shamsoddini A, Amirsalari S, Hollisaz MT, Rahimnia A, Khatibi-Aghda A. Management of spasticity in children with cerebral palsy. Iran J Pediatr. 2014;24(4):345-51. [PubMed: 25755853].

21. Guiard Y. Asymmetric division of labor in human skilled bimanual action: the kinematic chain as a model. J Mot Behav. 1987;19(4):486517. [PubMed: 15136274].

22. Arnould C, Penta M, Renders A, Thonnard JL. ABILHAND-Kids: a measure of manual ability in children with cerebral palsy. Neurology. 2004;63(6):1045-52. [PubMed: 15452296].

23. World Health Organization. . The international classification of functioning, disability and health- ICF. Geneva: WHO; 2001.

24. Stucki G, Ewert T, Cieza A. Value and application of the ICF in rehabilitation medicine. Disabil Rehabil. 2003;25(11-12):628-34. doi: 10.1080/09638280110070221. [PubMed: 12959337]

25. Dong VA, Tung IH, Siu HW, Fong KN. Studies comparing the efficacy of constraint-induced movement therapy and bimanual training in children with unilateral cerebral palsy: a systematic review. Dev Neurorehabil. 2013;16(2):133-43. doi: 10.3109/17518423.2012.702136. [PubMed: 22946588].

26. Sakzewski L, Ziviani J, Boyd R. The relationship between unimanual capacity and bimanual performance in children with congenital hemiplegia. Dev Med Child Neurol. 2010;52(9):811-6. doi: 10.1111/j.14698749.2009.03588.x. [PubMed: 20132142].

27. Arnould C, Penta M, Thonnard JL. Hand impairments and their relationship with manual ability in children with cerebral palsy. J Rehabil Med. 2007;39(9):708-14. doi: 10.2340/16151977-0111. [PubMed: 17999009].

28. Carlyne A, Massimo P, Jean-Louis T. Hand impairments and their relationshıp with manual ability in children with cerebral palsy.J Rehabil Med. 2007:39:708-14.

29. Lamonica DA, Paiva CS, Abramides DV, Biazon JL. Communication skills in individuals with spastic diplegia. Codas. 2015;27(2):135-41 doi: 10.1590/2317-1782/20152013060. [PubMed: 26107078]. 